ARTICLE

Received 10 Feb 2016 | Accepted 1 Jun 2016 | Published 1 Jul 2016

DOI: $10.1038 /$ ncomms12108

OPEN

\title{
Gas-solid interfacial modification of oxygen activity in layered oxide cathodes for lithium-ion batteries
} Bao Qiu ${ }^{1, \star}$, Minghao Zhang ${ }^{2, \star}$, Lijun Wu ${ }^{3, \star}$, Jun Wang ${ }^{4}$, Yonggao Xia ${ }^{1}$, Danna Qian ${ }^{2}$, Haodong Liu ${ }^{2}$, Sunny $\mathrm{Hy}^{2}$,
Yan Chen ${ }^{5}$, Ke An ${ }^{5}$, Yimei Zhu ${ }^{3}$, Zhaoping Liu ${ }^{1} \&$ Ying Shirley Meng ${ }^{2}$

Lattice oxygen can play an intriguing role in electrochemical processes, not only maintaining structural stability, but also influencing electron and ion transport properties in high-capacity oxide cathode materials for Li-ion batteries. Here, we report the design of a gas-solid interface reaction to achieve delicate control of oxygen activity through uniformly creating oxygen vacancies without affecting structural integrity of Li-rich layered oxides. Theoretical calculations and experimental characterizations demonstrate that oxygen vacancies provide a favourable ionic diffusion environment in the bulk and significantly suppress gas release from the surface. The target material is achievable in delivering a discharge capacity as high as $301 \mathrm{mAhg}^{-1}$ with initial Coulombic efficiency of $93.2 \%$. After 100 cycles, a reversible capacity of $300 \mathrm{mAh}^{-1}$ still remains without any obvious decay in voltage. This study sheds light on the comprehensive design and control of oxygen activity in transition-metal-oxide systems for next-generation Li-ion batteries.

\footnotetext{
${ }^{1}$ Ningbo Institute of Materials Technology and Engineering (NIMTE), Chinese Academy of Sciences, Zhejiang 315201, China. ${ }^{2}$ Department of Nano Engineering, University of California San Diego (UCSD), La Jolla, California 92093, USA. ${ }^{3}$ Department of Condensed Matter Physics and Materials Science, Brookhaven National Laboratory, Upton, New York 11973, USA. ${ }^{4}$ MEET Battery Research Center/Institute of Physical Chemistry, University of Müenster, Corrensstrasse 46, Müenster 48149, Germany. ${ }^{5}$ Chemical and Engineering Materials Division, Oak Ridge National Laboratory, Oak Ridge, Tennessee, 37830 USA. * These authors contributed equally to the work. Correspondence and requests for materials should be addressed to Z.L. (email: liuzp@nimte.ac.cn) or to Y.X. (email: xiayg@nimte.ac.cn) or to Y.S.M. (email: shirleymeng@ucsd.edu).
} 
T he functionality of many transition metal oxides can be significantly altered by oxygen vacancies on the surface. Oxygen vacancies can behave as charge carriers for solidoxide fuel cells ${ }^{1}$, as well as important adsorption sites and as active sites for electro-photocatalysts ${ }^{2}$. In Li-ion cathode materials, these vacancies play a vital role in determining the material's electron and ion transport properties ${ }^{3-5}$. The influence of oxygen vacancies at the surface on electrochemical performance can be completely different depending on the type of Li-ion cathode material ${ }^{6-8}$. Li-rich layered oxides, either as a solid solution or as a nano-composite of layered $\mathrm{Li}_{2} \mathrm{MnO}_{3}$ and $\mathrm{Li}(\mathrm{TM}) \mathrm{O}_{2}(\mathrm{TM}=\mathrm{Ni}, \mathrm{Co}, \mathrm{Mn})$, are drawing attention as nextgeneration cathode materials for high-energy-density Li-ion batteries in electric vehicles ${ }^{9-11}$. Over the past 20 years, the discharge capacity at room temperature of these cathode materials $\mathrm{s}^{9}, 14$ has been improved, from $200 \mathrm{mAh} \mathrm{g}^{-1}$, given in the first report ${ }^{12}$, to over $320 \mathrm{mAhg}^{-1}$ (ref. 14) today as summarized by $\mathrm{Hy}$ et al. ${ }^{15}$, and even higher at elevated temperatures ${ }^{16}$. While research has continued to push the limit of the available capacity of the materials over the years, debates on the origins of the ultrahigh capacity beyond the redox of transition metal have intensified recently.

Numerous studies ${ }^{10,17-23}$ exemplify the contributions of bulk and surface oxygen on high charge-discharge capacity in Li-rich layered oxides, although this hypothesis has not been fully verified. Tarascon and co-workers ${ }^{21,22}$ concluded that the extrahigh capacity is mainly attributable to reversible anionic redox processes $\left(\mathrm{O}^{2-} / \mathrm{O}_{2}^{2-}\right.$ or $\mathrm{O}^{2-} / \mathrm{O}_{2}{ }^{n-}$, where $\left.3>n>1\right)$ within the bulk of Li-rich layered oxides. Delmas and co-workers ${ }^{19,20}$ proposed that surface oxygen is oxidized to $\mathrm{O}_{2}$ gas and irreversibly lost from the structure, leaving some oxygen vacancies on the surface or in the sub-surface layers. Our previous work ${ }^{24-26}$ illustrated that oxygen vacancies generated during the high-potential electrochemical process can facilitate the transition metal ion migration and surface structural transformation, finally leading to their potential degradation during extended cycles.

To reduce oxygen gas generation and utilize reversible oxygen redox activity during charging and discharging, oxygen vacancies have been proposed to form on the surface of the as-synthesized Li-rich layered oxides before electrochemical processing. The influence of the surface oxygen vacancies on the oxygen gas generation is discussed in detail in Supplementary Note 1. The creation of surface oxygen vacancies was previously attempted utilizing a reducing atmosphere ${ }^{27,28}$ and leaching with acid accompanied by heat treatment ${ }^{29,30}$. However, the bulk structure reported in previous work easily transforms from a pure layered phase to spinel- and/or rock-salt phases ${ }^{28-33}$, which diminishes the rate capability and cycling stability.

Motivated by the considerations above, we propose a strategy based on a gas-solid interface reaction (GSIR) between Li-rich layered oxides and carbon dioxide gas to create oxygen vacancies on the particles' surface. The schematic of GSIR process between Li-rich layered oxides and carbon dioxide is displayed in Fig. 1a, and the procedure is detailed in the 'Methods' section. Oxygen vacancies in the surface regions up to 20 -nm thick are created on the particles without affecting structural integrity. After the surface modification, the target material $\mathrm{Li}\left[\mathrm{Li}_{0.144} \mathrm{Ni}_{0.136}\right.$ $\mathrm{Co}_{0.136} \mathrm{Mn}_{0.544} \mathrm{O}_{2}$ exhibits discharge capacity as high as $300 \mathrm{mAhg}^{-1}$ with no obvious voltage degradation after 100 cycles at a current density of $25 \mathrm{mAg}^{-1}$. As confirmed by both theoretical calculations and experimental characterization, the improved electrochemical performance is ascribed to the full utilization of oxygen activity through the creation of oxygen vacancies on the surface of the as-synthesized Li-rich layered oxides.

\section{Results}

Characterizations of oxygen vacancies after GSIR process. Li-rich layered oxide $\mathrm{Li}\left[\mathrm{Li}_{0.144} \mathrm{Ni}_{0.136} \mathrm{Co}_{0.136} \mathrm{Mn}_{0.544}\right] \mathrm{O}_{2}$ (denoted as LR-NCM) was prepared by a co-precipitation method (see the 'Methods' section). After the GSIR process is completed, the general morphology remains the same as in the pristine LR-NCM (Supplementary Fig. 1). Both synchrotron X-ray diffraction (SXRD) refinements and transition metal K-edge X-ray absorption near-edge structure show no major difference for the pristine and GSIR LR-NCM samples (Supplementary Figs 2 and 3). These results preliminarily imply that the GSIR process does not heavily influence the average crystal structures and bulk electronic environments of the LR-NCM sample.

To investigate the GSIR reaction mechanism of the formation of surface oxygen vacancies, we applied Fourier-transformed infrared spectroscopy (FTIR) and X-ray photoelectron spectroscopy (XPS) to three samples (Fig. 1b,c). The FTIR results (Fig. 1b) indicate that carbonate formed on their surfaces after the GSIR. The lithium concentration of the GSIR LR-NCM is slightly lower $(6.4 \%)$ than that of the pristine LR-NCM, as was determined by inductive coupled plasma-atomic emission spectrometry. On the other hand, in the oxygen 1s XPS spectra (Fig. 1c), the intensity of the binding energy at $529.5 \mathrm{eV}$ representing TM-O covalency for the GSIR LR-NCM after washing is much lower than that of the pristine LR-NCM. In contrast, the intensity of the binding energy at $531.5 \mathrm{eV}$ representing the carbonate group $\left(-\mathrm{CO}_{3}\right)$ for the GSIR LRNCM without washing is much larger ${ }^{34,35}$. Both changes indicate some lattice oxygen was extracted by $\mathrm{CO}_{2}$, forming oxygen vacancies on the sub-surfaces.

The amount of oxygen vacancies in the GSIR LR-NCM sample was determined by neutron diffraction (ND), a technique with high sensitivity for detecting light elements ${ }^{36}$, such as $\mathrm{Li}$ and $\mathrm{O}$. Figure 2a,b demonstrates the as-collected time-of-flight (TOF) ND patterns with 'Rietveld' refinement for both samples (patterns refined with a solid solution of ' $R-3 m$ ' symmetry; the normalized TOF ND patterns are shown in Supplementary Fig. 4). The lattice parameters of the pristine layer are $\mathrm{a}=2.8445(2) \AA$, and $c=14.2113(9) \AA$. The oxygen occupancy of the pristine LR$\mathrm{NCM}$ is $99.97 \pm 1.10 \%$. In comparison, the lattice parameters of the GSIR LR-NCM are $\mathrm{a}=2.8526(8) \AA$ and $\mathrm{c}=14.2503(7) \AA$, which are slightly larger than those of the pristine LR-NCM. The oxygen occupancy is reduced to $96.21 \pm 1.20 \%$ after surface modification. The amount of $\mathrm{Ni}^{2+}$ in the $\mathrm{Li}$ layer, and the occupancy of $\mathrm{Li}$ in the $\mathrm{Li}$ layer are also relatively larger than that of in the pristine LR-NCM. In addition, the data are also analysed using the two-phase model (the as-collected TOF ND patterns are shown in Supplementary Fig. 5), that is, a combination of $\mathrm{LiTMO}_{2}(R-3 m)$ phase, and $\mathrm{Li}_{2} \mathrm{MnO}_{3}(\mathrm{C} / 2 \mathrm{~m})$ phase. The results show that no oxygen vacancies $\left(\mathrm{V}_{\mathrm{O}}\right)$ are observed in the pristine LR-NCM sample, while the GSIR LR-NCM sample exhibits $7.20 \pm 3.3 \% \mathrm{~V}_{\mathrm{O}}$ on the $4 \mathrm{i}$ site and $3.8 \pm 3.0 \% \mathrm{~V}_{\mathrm{O}}$ on the $8 \mathrm{j}$ site in $\mathrm{Li}_{2} \mathrm{MnO}_{3}$ phase and $2.96 \pm 1.86 \% \mathrm{~V}_{\mathrm{O}}$ in the overall composition. Both models are consistent with the observed oxygen vacancies in the GSIR LR-NCM. The lower oxygen occupancy in the GSIR LR-NCM proves that the oxygen vacancies are successfully created after applying the GSIR process.

High-resolution transmission electron microscopy (TEM; Fig. 2c,f) was used to further illustrate the changes between the pristine and GSIR LR-NCM. A clean surface with Li and TM layers extending to the very edge of atomic planes is observed in the pristine LR-NCM (Fig. 2c). Meanwhile, a non-uniform surface (varying in thickness from 10 to $20 \mathrm{~nm}$ ) is detected on the GSIR LR-NCM sample. In addition, high-angle annular-darkfield scanning-TEM images (Fig. 2d,g) for the pristine and GSIR LR-NCM are compared to demonstrate the lack of any obvious 
a

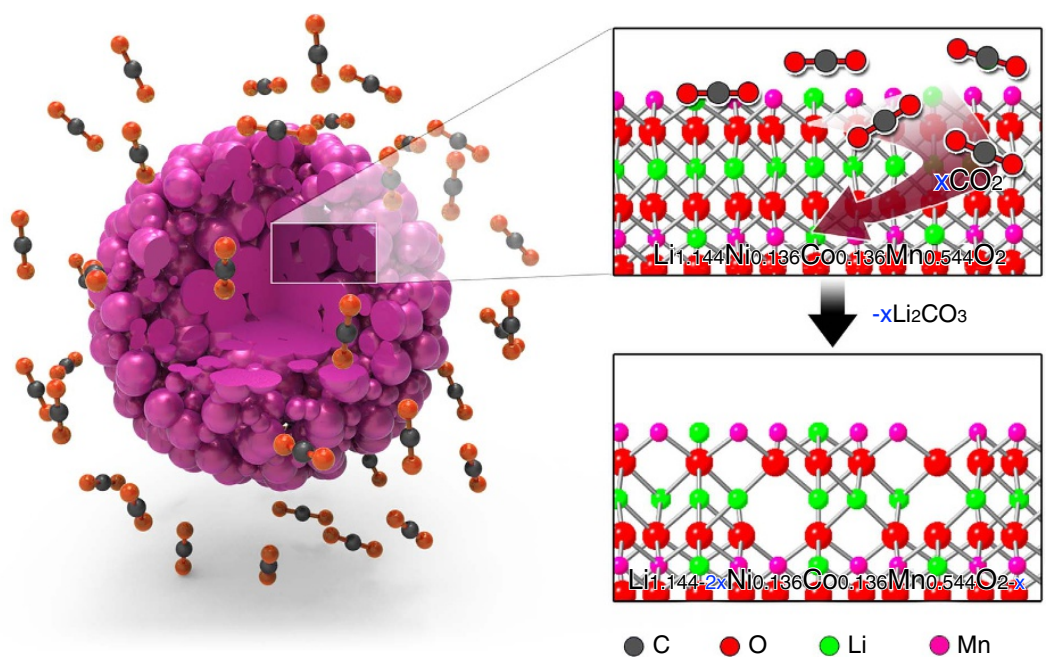

b

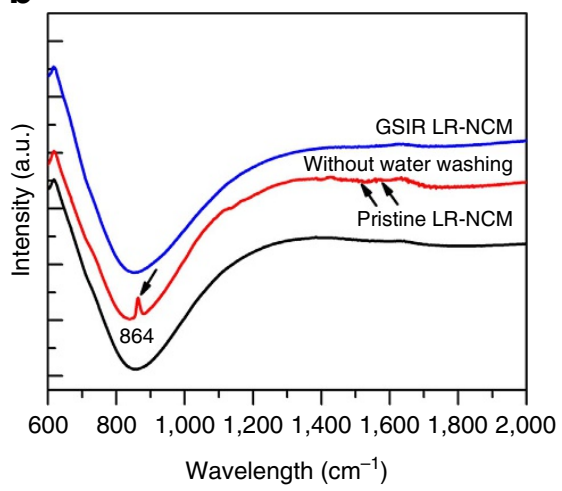

C

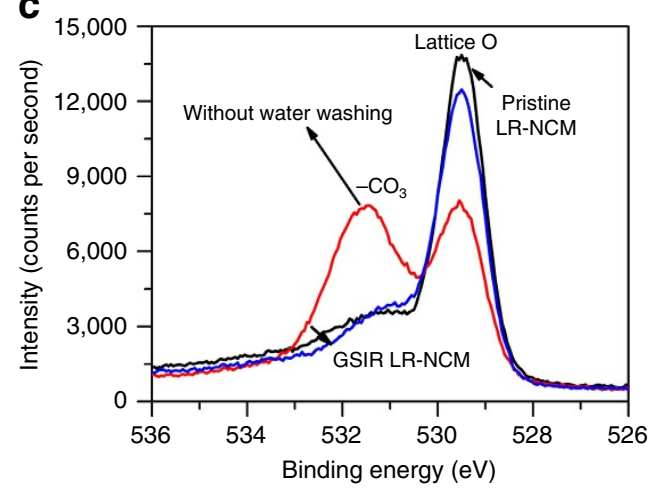

Figure 1 | GSIR. (a) Schematic of GSIR between Li-rich layered oxides and carbon dioxide. (b) FTIR spectrum. The GSIR LR-NCM without water washing (red line), compared with the pristine LR-NCM, has three additional peaks, corresponding to the IR-active modes of $-\mathrm{CO}_{3}$. The sharp peak $\left(864 \mathrm{~cm}{ }^{-1}\right)$ is the $\mathrm{CO}_{3}$ group bending mode, while the other two peaks $\left(1,438\right.$ and 1,500 $\mathrm{cm}^{-1}$ ) are from the $\mathrm{C}-\mathrm{O}$ asymmetric and symmetric stretching modes; (c) XPS spectra of the $\mathrm{O}$ 1s. It is clear that the GSIR LR-NCM has lower intensity than that of the pristine LR-NCM at lower-banding energy, which indicates some lattice $\mathrm{O}$ has been extracted by $\mathrm{CO}_{2}$.

structural change. Although electron diffraction from some particles shows spinel/rock-salt-like phase in the GSIR LR-NCM compared with the pristine LR-NCM sample (Fig. 2e,h), it should be noted this phase transformation only occurs on the surface of GSIR LR-NCM within several atomic layers, as indicated in Fig. 2f, while the oxygen vacancy presence are $10-20-\mathrm{nm}$ deep. These results are consistent with our SXRD and ND refinements, which verify that the GSIR process does not significantly alter the bulk structure.

Electron energy-loss spectroscopy (EELS) mapping was applied to compare relative surface composition changes for the pristine and GSIR LR-NCM sample (Fig. 3a,b). Oxygen reduction at mixed colour images is well-demonstrated on the edge of GSIR LR-NCM in comparison with the pristine LR-NCM. To study the electronic states of oxygen and transition metal from the particle, EELS was collected at different positions from bulk to surface of the GSIR LR-NCM (represented by colours in Fig. 3c,d). The spectra of the O-K-edge main peaks in Fig. 3e are normalized with the $\mathrm{Mn} \mathrm{L}_{3}$ peak. Interestingly, it is observed that reduced $\mathrm{O}$ pre-peak intensities are from the surface in the GSIR LR-NCM sample. The weak pre-peak intensities can be even seen at $20 \mathrm{~nm}$ for the GSIR LR-NCM sample although the difference is small. The reduced ratio of the O-K-edge pre-peak intensities to the main peak can result from a change in the local environment of oxygen, especially from the oxygen vacancies formed on the surface $^{26,37}$. The relative distribution of chemical composition is plotted in Fig. 3f. The content of $\mathrm{O}$ on average is $55 \%$ in the first $10 \mathrm{~nm}$ surface layer compared with the bulk value of $65 \%$. The $\mathrm{Mn} \mathrm{L}_{3,2}$ white lines provide information on $\mathrm{Mn}$ valence (oxidation); The Mn $\mathrm{L}_{3,2}$ white lines for the GSIR LR-NCM sample display a significant energy shift, and their $\mathrm{L}_{3} / \mathrm{L}_{2}$ intensity ratio remains low until $20 \mathrm{~nm}$ away from the surface of the GSIR LR-NCM sample (Fig. 3g), indicating a lower Mn valence on the particles' surface. When oxygen vacancies are created on the particles' surface, the valence of $\mathrm{Mn}$ is reduced simultaneously with the extraction of $\mathrm{Li}$ to compensate for the changes in charge. Therefore, as confirmed by both the ND and STEM/EELS results, oxygen vacancies have been successfully introduced on the $10-20 \mathrm{~nm}$ of the surface without a noticeable interruption in the bulk structure through the GSIR approach.

Electrochemical properties of the pristine and GSIR LR-NCM. CR2032 coin cells with metallic $\mathrm{Li}$ as the counter electrode were assembled to investigate the electrochemical performance of the pristine and GSIR LR-NCM samples. Similar to other Li-rich layered oxides, both of them (Fig. 4a) exhibit a long plateau region at $\sim 4.5 \mathrm{~V}$ versus $\mathrm{Li}^{+} / \mathrm{Li}^{0}$, which usually is ascribed to the 
a
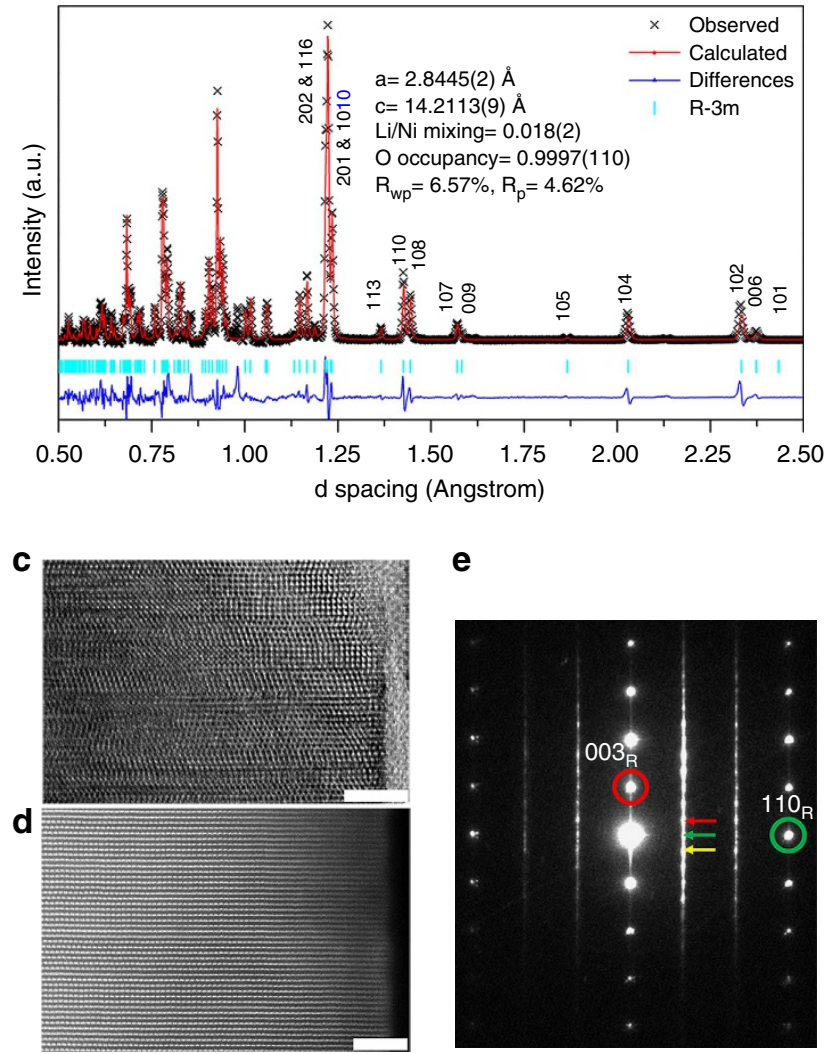

e

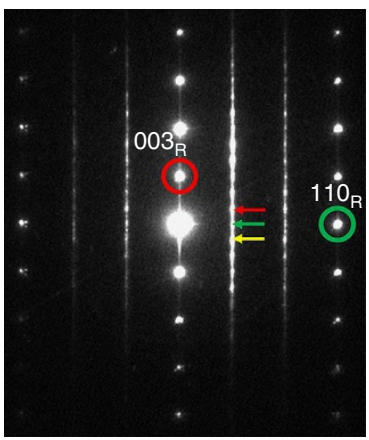

b

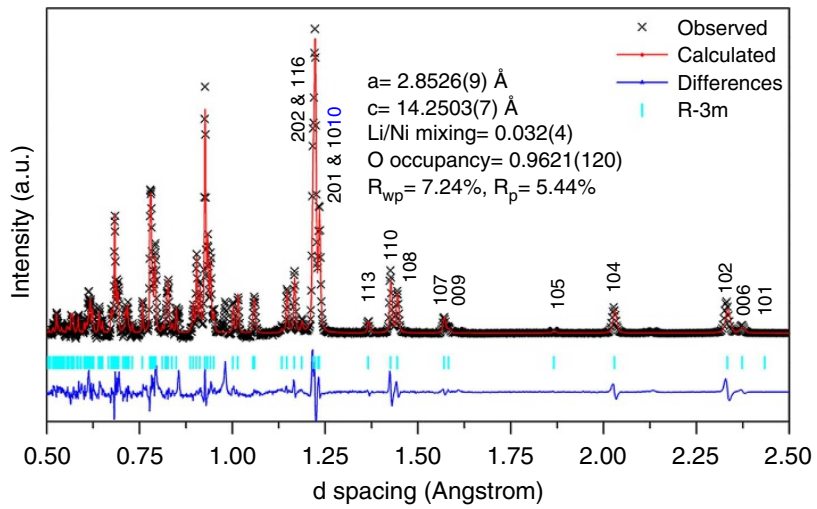

f

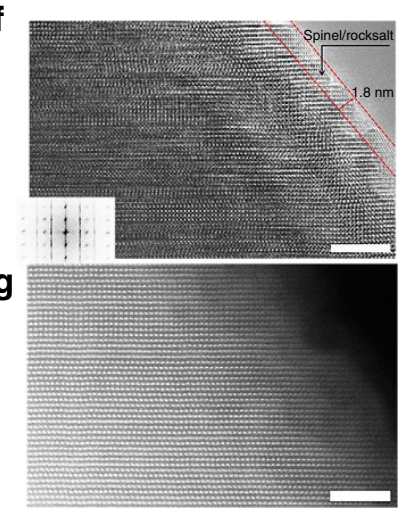

h

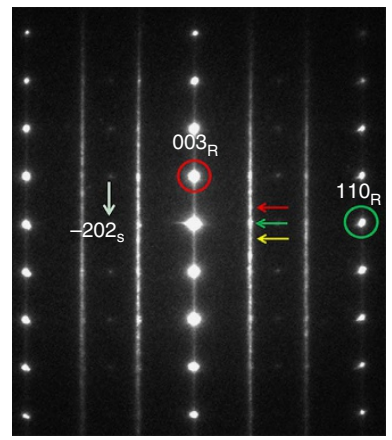

Figure 2 | Structural characterizations of the pristine and GSIR LR-NCM. (a,b) TOF ND patterns for the pristine and GSIR LR-NCM. On the basis of these results, the oxygen vacancy for the GSIR LR-NCM is around three per cent higher than that of the pristine LR-NCM sample; (c) high-resolution transmission electron microscopy (HRTEM) image and, (d) high-angle annular dark-field-STEM (HAADF-STEM) image for the pristine LR-NCM; (e) electrondiffraction (ED) pattern for the pristine LR-NCM. The elongation of these spots are along $[001]_{R}{ }^{\star}$ as well as $[001]_{M}{ }^{\star}$ direction. The spots indicated with red, green and yellow arrows represent $(110),(020)$ and $(-110)$ of the monoclinic $\mathrm{Li}_{2} \mathrm{MnO}_{3}$ (donated as $\mathrm{M}$ ) variants $[1-10]_{\mathrm{M}},[100]_{\mathrm{M}}$ and $[110]_{\mathrm{M}}$, respectively. The spot marked by a red circle is shared by $(003)_{R}$ of the rhombohedral (donated as R), as well as the structure $(001)_{M}$ of all monoclinic variants. The spot marked by a green circle is shared by $(110)_{R}$ of the rhombohedral, as well as the structure $(33-1)_{M}(060)_{M}$ and $(-331)_{M}$ of the monoclinic. $(\mathbf{f})$ HRTEM image with fast Fourier transform (FFT) about the surface and (g). HAADF-STEM image for the GSIR LR-NCM; (h) ED for the GSIR LR-NCM. The weak spot indicated by the white arrow can only be indexed as the structure $(-202)_{S}$ of the spinel (donated as S). Scale bars, $5 \mathrm{~nm}$.

electrochemical activation of the $\mathrm{Li}_{2} \mathrm{MnO}_{3}$ component during the initial charge process ${ }^{38-40}$, although an electrolyte/electrode side reaction is expected in this region. Interestingly, the value of the initial discharge capacity for the GSIR LR-NCM can reach as high as $301 \mathrm{mAhg}^{-1}$ compared with that of $276 \mathrm{mAhg}^{-1}$ for the pristine LR-NCM. The initial coulombic efficiency also increases from 83.8 to $93.2 \%$. The corresponding differential capacity versus voltage $(\mathrm{d} Q / \mathrm{d} V)$ curves are plotted in Fig. $4 \mathrm{~b}$. A lower shift in the oxidation peak after the GSIR process is due to the decrease in electrochemical impedance (Supplementary Fig. 6 and Supplementary Table 1). In addition, the decline of the oxidation peak around $4.5 \mathrm{~V}$ versus $\mathrm{Li}^{+} / \mathrm{Li}^{0}$ observed in the enlarged $\mathrm{dQ} / \mathrm{d} V$ curves (inset in Fig. 4b) indicates that the GSIR process has pre-activated the $\mathrm{Li}_{2} \mathrm{MnO}_{3}$ component responsible for the $4.5 \mathrm{~V}$ plateau. The rate capability and cycling stability further highlight the advantages of our GSIR LR-NCM sample (Fig. 4c). At all tested rates, the GSIR LR-NCM exhibits a higher capacity than that of the pristine LR-NCM. The unique characteristic at different rates for the GSIR LR-NCM is that the additional discharge capacity (Supplementary Fig. $7 \mathrm{a}-\mathrm{f}$ ) results only from the lower-potential region $\left(<3.5 \mathrm{~V}\right.$ versus $\left.\mathrm{Li}^{+} / \mathrm{Li}^{0}\right)$. It is remarkable that the GSIR LR-NCM delivers a higher discharge capacity of $298 \mathrm{mAhg}^{-1}$ when it returns to the $0.1 \mathrm{C}$-rate, compared with that of $288 \mathrm{mAhg}^{-1}$ for the pristine LR-NCM.
More importantly, the charge-discharge plots at subsequent cycles (Supplementary Fig. 7g,h) for the GSIR LR-NCM demonstrate a slight degradation in potential after 100 cycles, even for a discharge capacity as high as $300 \mathrm{mAh} \mathrm{g}^{-1}$. To track the origin of the additional capacity after the GSIR, the energy density and discharge capacity below and above $3.5 \mathrm{~V}$ versus $\mathrm{Li}^{+} / \mathrm{Li}^{0}$ are plotted as a function of the cycle number, as depicted in Supplementary Fig. 8i,j. It proves that the additional capacity in discharge capacity also comes from the lower-potential region $\left(<3.5 \mathrm{~V}\right.$ versus $\left.\mathrm{Li}^{+} / \mathrm{Li}^{0}\right)$.

To evaluate the stability of the GSIR LR-NCM, a more challenging measurement was selected (Fig. 4d,e). Cells based on the GSIR LR-NCM show a higher initial capacity of $306 \mathrm{mAh} \mathrm{g}^{-1}$ (0.5 C-rate) and $280.9 \mathrm{mAh} \mathrm{g}^{-1}$ (1.0 C-rate), compared with that of $287 \mathrm{mAh} \mathrm{g}^{-1}\left(0.5 \mathrm{C}\right.$-rate) and $269 \mathrm{mAhg}^{-1}$ (1.0 C-rate) for the pristine LR-NCM at the elevated temperature of $55^{\circ} \mathrm{C}$. The initial charge-discharge curves (Supplementary Fig. 8a,b) are similar to the results at room temperature (Fig. 4a). In addition, the cells based on the pristine LR-NCM display only $223 \mathrm{mAhg}^{-1}$ (at $0.5 \mathrm{C}$-rate) and $179 \mathrm{mAhg}^{-1}$ (at $1.0 \mathrm{C}$-rate) after 100 cycles and 150 cycles, respectively, whereas the GSIR LR-NCM shows an excellent capacity of about $290 \mathrm{mAhg}^{-1}$ (at $0.5 \mathrm{C}$-rate) and $262 \mathrm{mAhg}^{-1}$ (at $1.0 \mathrm{C}$-rate) during the same cycling period. Moreover, the charge-discharge plots of 


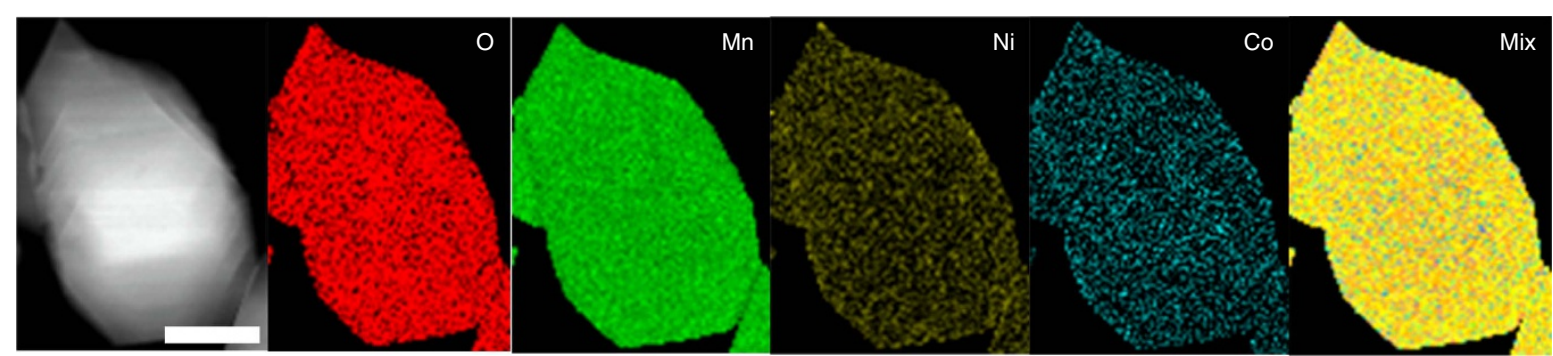

b

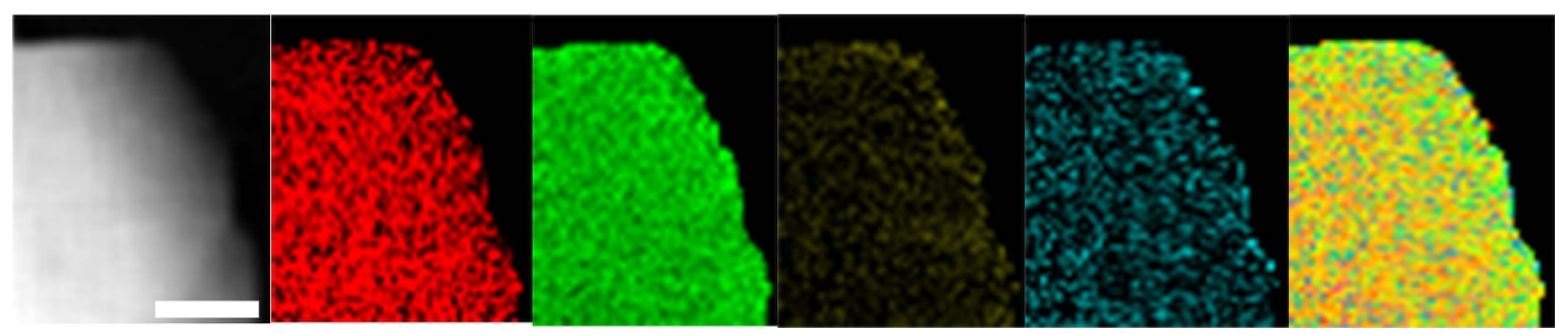

C

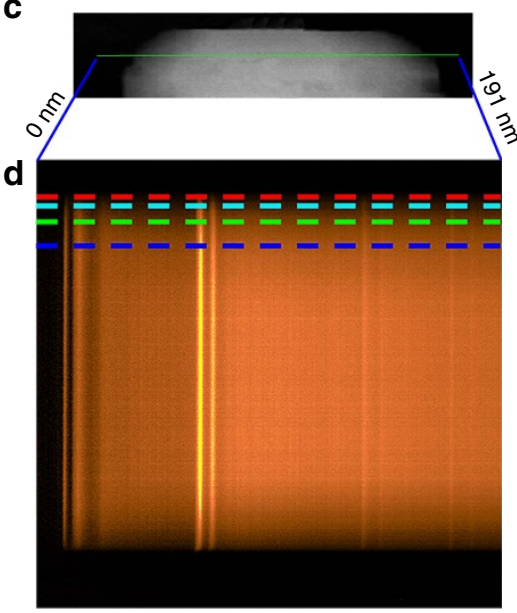

f

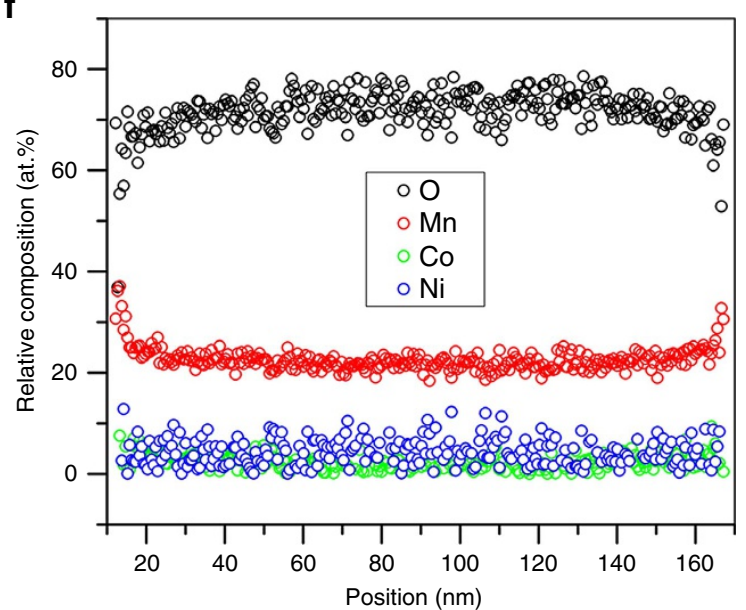

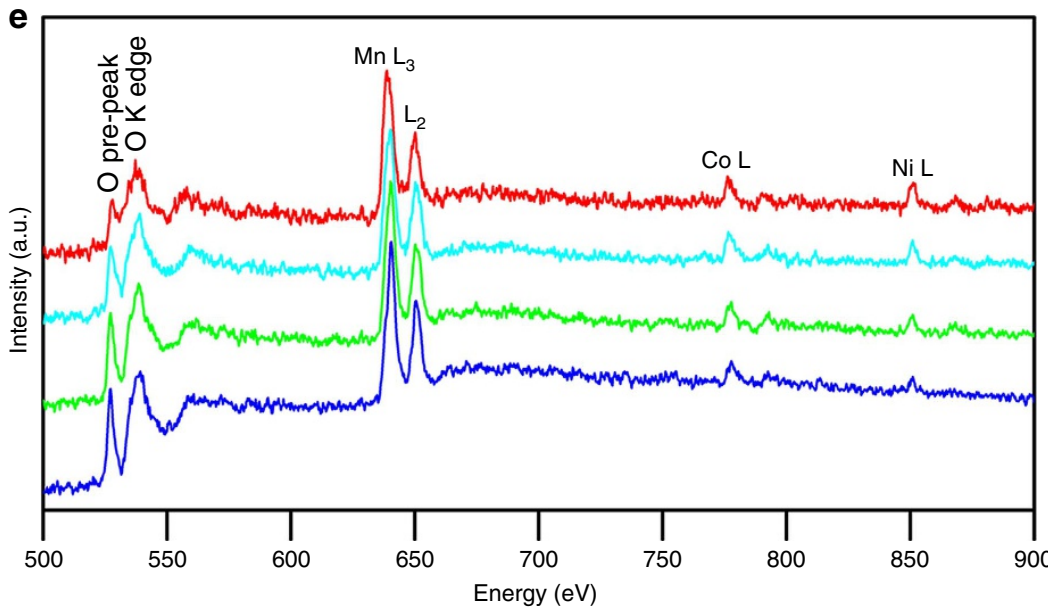

g

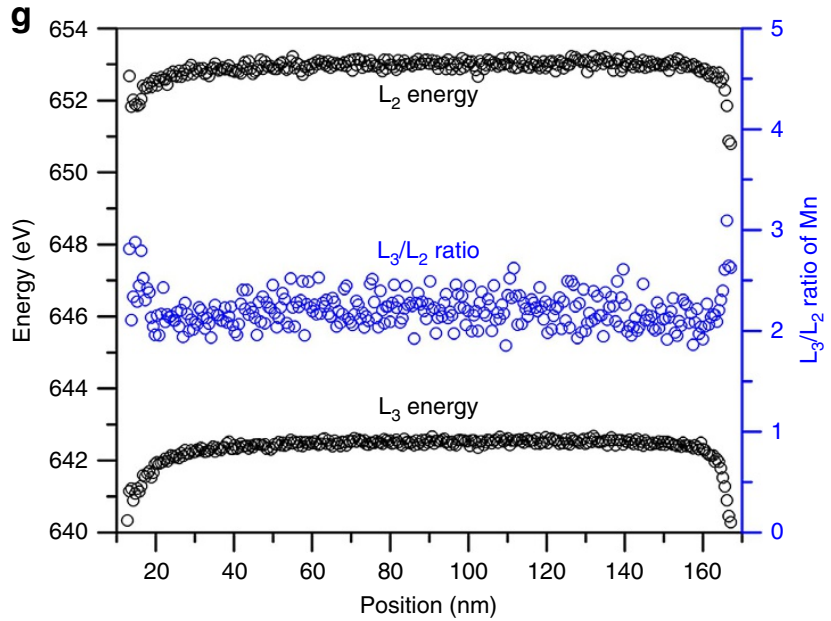

Figure 3 | Relative surface composition changes for the pristine and GSIR LR-NCM. (a) STEM-EELS spectrum images for the pristine LR-NCM. Scale bar, $50 \mathrm{~nm}$. (b) The GSIR LR-NCM. Scale bar, $25 \mathrm{~nm}$. Oxygen reduction at mixed colour images is well-demonstrated on the edge in comparison with the pristine LR-NCM (a). (c) STEM image of a particle of the GSIR LR-NCM. (d) EELS spectrum image from the vertical green line (0-191 nm) in the left STEM image (c), showing $\mathrm{OK}, \mathrm{MnL}_{2,3}, \mathrm{Co}_{2,3}, \mathrm{Ni}_{2,3}$ edges. The dispersion is $0.25 \mathrm{eV} / \mathrm{channel}$. The scan step is $0.127 \mathrm{~nm}$. (e) EELS spectrum profiles from the surface to the interior as marked by the horizontal dashed lines with the same colour as in $\mathbf{d}$. The spectra are normalized with $M n L_{3}$ peak, and each spectrum was averaged vertically with 10 individual spectra to improve the signal noise ratio. Weak $\mathrm{O}$ pre-peak on the surface indicates the oxygen vacancies are formed. (f) Relative atomic composition of O (black), Mn (red), Co (blue) and Ni (green) as a function of position calculated based on the integrated EELS peak intensity in e. (g) $M n L_{3}$, and $L_{2}$ energy (top and bottom of panel) from refinement, and $L_{3} / L_{2}$ intensity ratio. 

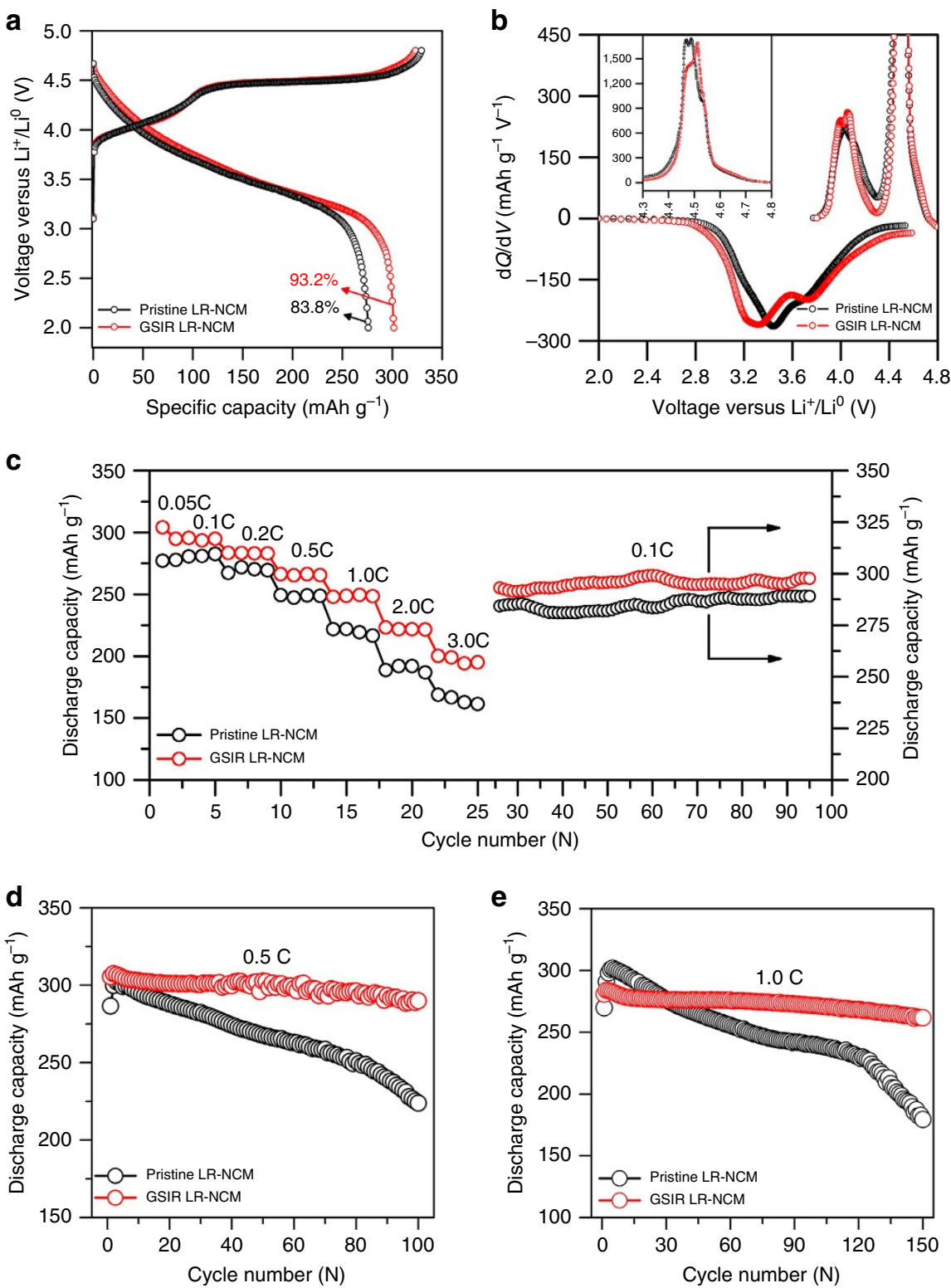

Figure 4 | Charge-discharge characteristics of the pristine and GSIR LR-NCM. (a) First charge-discharge profiles of the pristine and GSIR LR-NCM obtained from a 2032-type coin cells at 0.05 C-rate, where 1.0 C-rate corresponds to the current density of $250 \mathrm{mAg}^{-1}$. (b) Differential capacity (dQ/dV) plots of the initial cycle curves of the pristine and GSIR LR-NCM. The inset shows the enlarged $d Q / d V$ curves about $4.5 \mathrm{~V}$. (c) Discharge-rate capacity after charging galvanostatically at $0.1 \mathrm{C}$-rate before each discharge. The capacity retention when performing charge-discharge cycles at constant $0.1 \mathrm{C}$-rate for 70 cycles after all rates tested. (d,e) Cycling performance of the pristine and GSIR LR-NCM at $55^{\circ} \mathrm{C}$ by applying a constant current density of $0.5 \mathrm{C}$-rate and $1.0 \mathrm{C}$-rate $\left(250 \mathrm{~mA} \mathrm{~g}^{-1}\right)$, respectively. The loading density of the active material on the electrode was around $5.5 \mathrm{mg} \mathrm{cm}-2$. It is noticeable that the electrochemical data are derived from the average value of at least five coin cells, and the errors on the specific capacity are about $3 \mathrm{mAhg}{ }^{-1}$.

subsequent cycles (Supplementary Fig. 8d,f) for the GSIR LR-NCM exhibit much slower potential degradation profiles at different rates than those of the pristine LR-NCM (Supplementary Fig. 8c,e). The difference clearly signifies that surface oxygen vacancies introduction in Li-rich layered oxides without severe structural destruction has a considerable effect on improving electrochemical performance.

\section{Discussion}

The influence of surface oxygen vacancies introduced by the GSIR process on the electrochemical performance can be discussed in two aspects. (1) The generation of highly reactive oxygen radicals on the particles' surface during the electrochemical process, which determines the electrochemical resistance at the electrode/ electrolyte interface; (2) the participation of the oxygen reaction in the form of $\mathrm{O}^{2-} / \mathrm{O}^{-}$or $\mathrm{O}_{2}{ }^{2-}$ in the bulk of the material, which are the dominant factors in compensating for extra electrons on the superior capacity of Li-rich layered oxides.

First, operando differential electrochemical mass spectrometry (DEMS) experiments were performed to evaluate the gas evolution during the initial charge-discharge process (Fig. 5a), which is largely related to the activity of oxygen on the particles' surface ${ }^{18,41,42}$. Irrespective of the cycling profile, as shown in Fig. $5 \mathrm{~b}, \mathrm{O}_{2}$ is detected near $4.5-4.6 \mathrm{~V}$ versus $\mathrm{Li}^{+} / \mathrm{Li}^{0}$ for both the pristine and GSIR LR-NCM; however, the $\mathrm{O}_{2}$ gas released from the GSIR LR-NCM electrode is much less than that of the pristine electrode. It is suggested that the formation of oxygen vacancies 


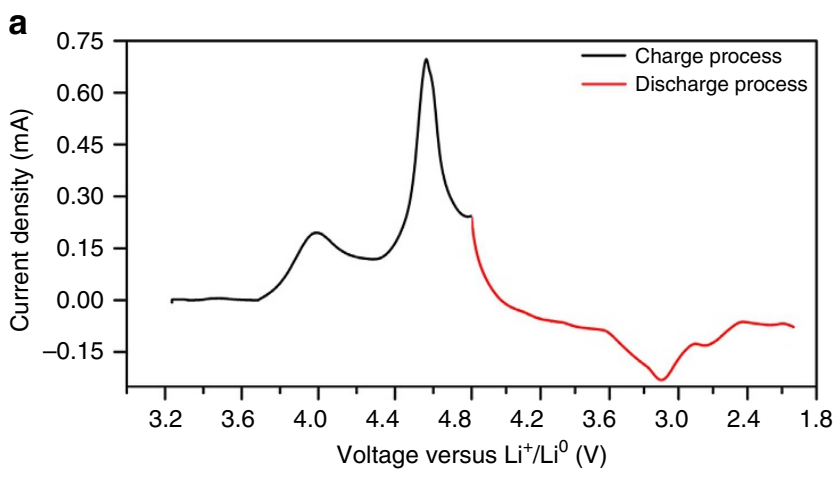

b

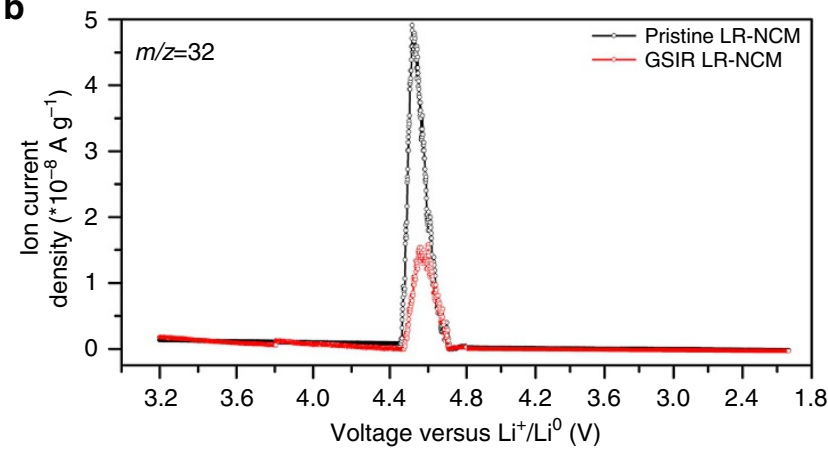

C

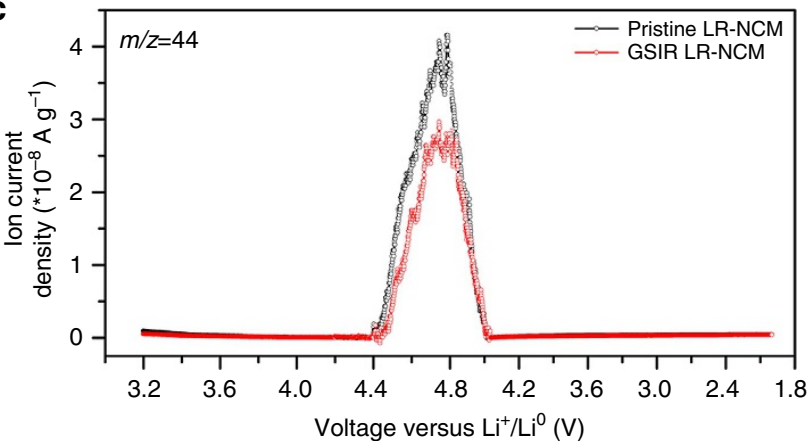

Figure 5 | Operando DEMS. (a) Initial cyclic voltammetry (CV) curve of the pristine and GSIR LR-NCM electrode. (b) Oxygen gas profile of the initial charge-discharge process for the pristine and GSIR LR-NCM electrode.

(c) Carbon dioxide gas profile of the initial charge-discharge process as the above electrodes. The loading density mass for these two electrodes are the same about $7.76 \mathrm{mg}$. The scan rate was $\sim 0.1 \mathrm{mVs}^{-1}$, and the potential range was between 2.0 and $4.8 \mathrm{~V}$ versus $\mathrm{Li}^{+} / \mathrm{Li}^{0}$ at an elevated temperature of $55^{\circ} \mathrm{C}$.

through GSIR could greatly suppress the evolution of $\mathrm{O}_{2}$ gas. According to the equation $P_{\mathrm{O}_{2}}=K\left[V_{\ddot{O}}\right]^{-6} / 16$ in the Supplementary note 1 , less $\mathrm{O}_{2}$ gas will be released due to the reduced partial pressure of oxygen on the surface of the GSIR LR-NCM electrode after oxygen vacancies are created. At the same time, the released $\mathrm{CO}_{2}$ gas for the GSIR LR-NCM (Fig. 5c), which is usually considered as the source of decomposition of the electrolyte at high potentials ${ }^{42}$, is smaller than that of the pristine LR-NCM. Therefore, the oxygen vacancies on the surface can hinder the highly reactive oxygen radicals from generating during the electrochemical process.

Second, the GSIR LR-NCM sample exhibits almost the same capacity in the plateau region as in the pristine sample with much less oxygen redox participation on the surface. To compensate for ionic changes during the charge process, more oxygen reactions in the form of $\mathrm{O}^{2-} / \mathrm{O}^{-}$or $\mathrm{O}^{2-}$ (instead of the $\mathrm{O}^{2-} / \mathrm{O}_{2}$ redox couple) are triggered in the bulk of the GSIR LR-NCM. The influence of the bulk oxygen activity in the diffusivity of lithium ions was investigated by first-principles calculations. For simplicity, the supercell was defined as $\mathrm{Li}_{28} \mathrm{Ni}_{6} \mathrm{Mn}_{14} \mathrm{O}_{48}$, which was adopted as a computational model in the previous work ${ }^{24}$. A specific $\mathrm{Li}_{20 / 28}$ concentration was chosen to simulate the last stage of discharge (below $\sim 3.2 \mathrm{~V}$ ), in which the GSIR LR-NCM demonstrates the biggest difference in electrochemical performance compared with the pristine LR-NCM. This stage is also generally acknowledged as a rate-determining step of the whole discharge process in Li-rich layered oxides ${ }^{43}$. In this stage, the Li-ion migrates from the octahedral site of the Li layer into the octahedral site of the adjacent transition metal layer through an empty tetrahedral site in the former (as shown in Fig. 6a). When no oxygen vacancy is introduced, the Li tetrahedron site, which is face-sharing with the TM layer $\mathrm{Li}$, is most stable. There is a high chance of trapping the Li-ion in the tetrahedral site (so-called 'Li-Li dumbbell') without diffusing into the adjacent octahedral site in the transition metal layer ${ }^{24}$. These dumbbells finally block the pathways of lithium diffusion, thereby decreasing ionic conductivity. In contrast, when oxygen vacancies are introduced the under-coordinated site is no longer stable, and the migration barrier is either zero or only around $170-210 \mathrm{meV}$ (ref. 44). The trapped Li-ion has a higher chance of escaping from the tetrahedral sites and continuing its diffusion process.

Overall, Fig. 6b,e summarizes the proposed reaction mechanism for the pristine and GSIR LR-NCM during charging and discharging. Before charging, uniform oxygen and lithium vacancies are created on the particle surface of the GSIR LR-NCM, accompanied by the pre-activation of certain amount of the $\mathrm{Li}_{2} \mathrm{MnO}_{3}$ component. The sloped region $(<4.4 \mathrm{~V})$ of the charging curve is attributed to the extraction of $\mathrm{Li}^{+}$ions from the lithium layer. No difference is expected between the pristine and GSIR LR-NCM material during this process. During the charging plateau region, more lithium ions can be extracted from the $\mathrm{Li}_{2} \mathrm{MnO}_{3}$ component, together with the oxidation of lattice oxygen ${ }^{19,20,22,23}$. The pre-activated surface layer of the GSIR sample with oxygen vacancies reduces the partial pressure of oxygen on the surface, and then prevents gaseous oxygen from evolving during plateau charging. A thinner SEI layer is thus expected to form on the particles' surface of the GSIR LR-NCM due to less side reactions between released oxygen and the electrolyte species, thereby decreasing the electrochemical resistance at the electrode/electrolyte interface, as supported by our electrochemical impedance-spectroscopy (EIS) results (Supplementary Fig. 6 and Supplementary Table 1). At the same time, the more reversible oxygen redox-reaction is triggered in the bulk of the GSIR LR-NCM during the high-potentialcharging process. These oxygen vacancies can activate the $\mathrm{Li}$ trapped in the tetrahedral sites to provide a favourable environment for Li-ion diffusion during the rate-determining step (the last stage of discharging). Higher levels of Li-ion diffusivity in the bulk, together with smaller resistance to chargetransfer and larger numbers of activated $\mathrm{Mn}^{4+} / \mathrm{Mn}^{3+}$ couples lead to higher capacity and better rate capability of the GSIR LR-NCM sample. Furthermore, minimal structure changes enable the superior cycling stability after GSIR modification.

In summary, a facile but effective approach to surface modification based on GSIR has been applied to create oxygen vacancies homogeneously without causing structural destruction. Oxygen vacancies in the surface regions up to $20-\mathrm{nm}$ thick are found to facilitate $\mathrm{Li}$ diffusion by activating the $\mathrm{Li}$ in the tetrahedral sites and suppress the release of gas from the surface, which finally lead to higher discharge capacity and a better rate capability in the Li-rich layered oxides. To the best of our knowledge, this study also clarifies for the first time the critical 
a

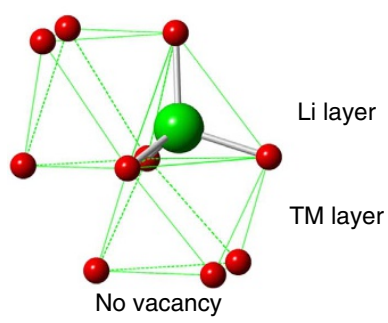

b

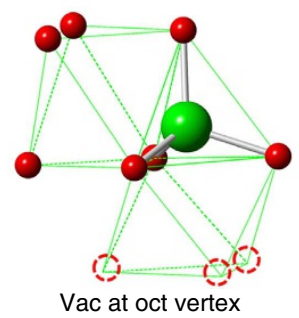

C

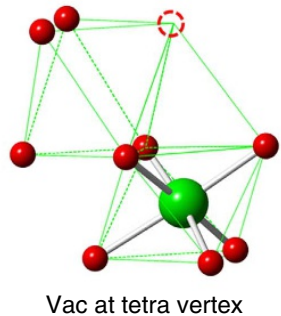

Vac at tetra vertex

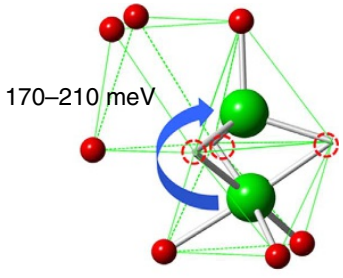

Vac at shared plane

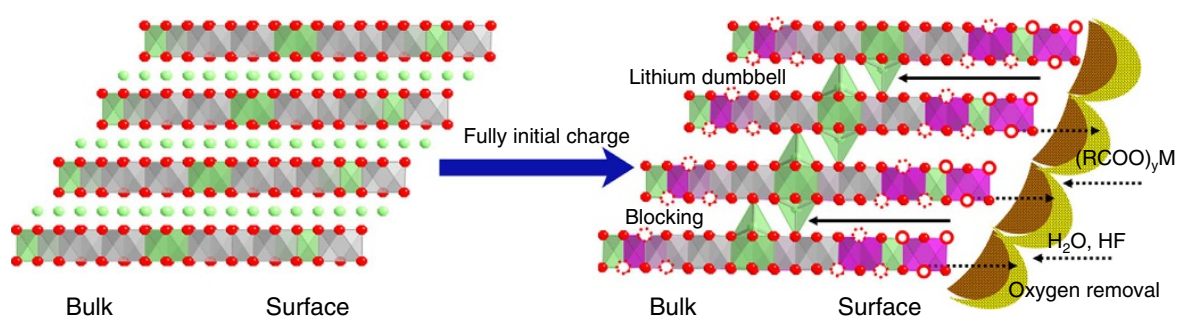

d

e

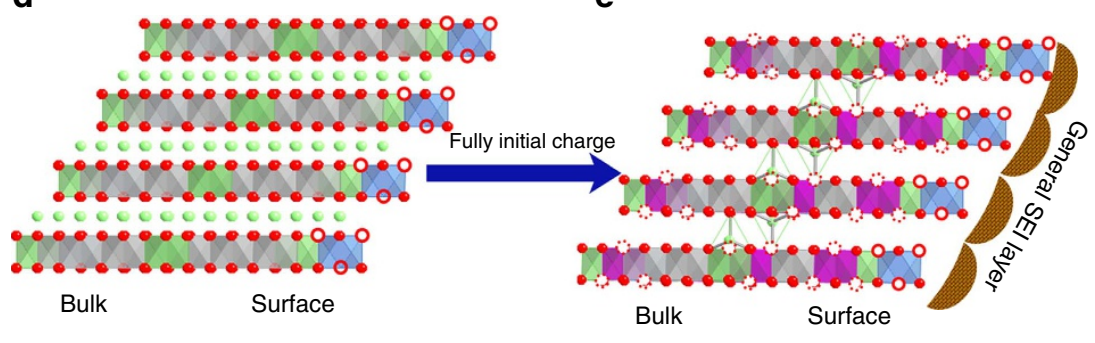

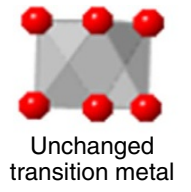

Chem/EC activated oxygen vacancy

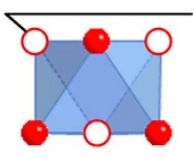

Chem activated transition metal

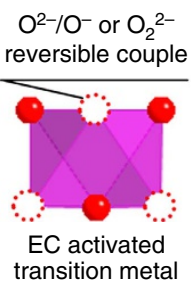

Figure 6 | Reaction mechanisms during charging and discharging. (a) Calculated site stability and activation barrier under conditions of no vacancy, vacancy at octahedron (Oct) vertex, vacancy (Vac) at tetrahedron (Tetra) vertex and vacancy (Vac) at shared plane. (b,c). The pristine LR-NCM before charging and after full initial charge. (d,e) The GSIR LR-NCM before charging and after full initial charge. Green, Li; red, O. The fundamental contribution of the novel surface modification is the uniform creation of lithium and oxygen vacancies on the surface of particles before electrochemical cycling. Consequently, more $\mathrm{Mn}^{4+} / \mathrm{Mn}^{3+}$ redox couples in $\mathrm{Li}_{2} \mathrm{MnO}_{3}$ component are pre-activated; less oxygen gas is released from the material and less oxygen vacancies are created in the bulk during the charging process; limited electrode/electrolyte corrosion and bulk material structure transformation are formed in the battery system.

influence of the activity of surface oxygen in enhancing the electrochemical performance. We believe this facile, scalable and inexpensive approach opens a door for comprehensive designing and controlling oxygen activity in transition-metal-oxide systems to achieve excellent energy and power density in their commercial applications.

\section{Methods}

Synthesis of $\mathrm{Li}_{[}\left[\mathrm{LO}_{\mathbf{0 . 1 4 4}} \mathbf{N i}_{\mathbf{0 . 1 3 6}} \mathrm{Co}_{\mathbf{0 . 1 3 6}} \mathbf{M n}_{\mathbf{0 . 5 4 4}}\right] \mathrm{O}_{\mathbf{2}}$. The synthesis procedures of $\mathrm{Li}\left[\mathrm{LO}_{0.144} \mathrm{Ni}_{0.136} \mathrm{Co}_{0.136} \mathrm{Mn}_{0.544}\right] \mathrm{O}_{2}$ were detailed as follows ${ }^{45}$ : we pumped an aqueous solution containing $\mathrm{NiSO}_{4} \cdot 6 \mathrm{H}_{2} \mathrm{O}, \mathrm{CoSO}_{4} \cdot 7 \mathrm{H}_{2} \mathrm{O}$ and $\mathrm{MnSO}_{4} \cdot 4 \mathrm{H}_{2} \mathrm{O}$ with a concentration of $2.0 \mathrm{moll}^{-1}$ into a continuously stirred tank reactor (CSTR, capacity of $50 \mathrm{l}$ ); at the same time, a $2.0 \mathrm{moll}^{-1} \mathrm{Na}_{2} \mathrm{CO}_{3}$ solution and a $0.2 \mathrm{moll}^{-1}$ $\mathrm{NH}_{4} \mathrm{OH}$ solution were added separately into the reactor. The co-precipitation temperature was held at $60^{\circ} \mathrm{C}$, and the $\mathrm{pH}$ value was fixed to 7.8 . The resulting $\left(\mathrm{Ni}_{1 / 6} \mathrm{Co}_{1 / 6} \mathrm{Mn}_{4 / 6}\right) \mathrm{CO}_{3}$ powders were washed several times with distilled water to remove residual $\mathrm{Na}^{+}$, and dried in a vacuum oven at $80^{\circ} \mathrm{C}$ for over $20 \mathrm{~h}$. The resulting precipitates were mixed with $\mathrm{Li}_{2} \mathrm{CO}_{3}$ and the exact molar ratio between them was 0.7 . The mixed powders were first pre-treated at $500^{\circ} \mathrm{C}$ for $5 \mathrm{~h}$ in the air and then calcinated at $850^{\circ} \mathrm{C}$ for $15 \mathrm{~h}$ in the air. Then, they were cooled to room temperature in the furnace. The as-obtained sample was labelled as pristine LR-NCM.

GSIR process. The GSIR process of the pristine LR-NCM sample with $\mathrm{CO}_{2}$ was carried out as follows: a set amount of LR-NCM cathode materials and a given amount of $\mathrm{NH}_{4} \mathrm{HCO}_{3}$, which is as the source of $\mathrm{CO}_{2}$ after decomposition at certain temperatures, were placed in an enclosed reactor in an argon-filled glove box
$\left(\mathrm{O}_{2}<0.1\right.$ p.p.m. $)$ with a total volume of $100 \mathrm{ml}$, and heated at $200^{\circ} \mathrm{C}$ for $10 \mathrm{~h}$. The optimal molar ratio between carbon dioxide and Li-rich layered oxides was about 1:5. It is important that the pristine LR-NCM cathode materials and the $\mathrm{NH}_{4} \mathrm{HCO}_{3}$ must be separated at the beginning for ensuring a homogeneous GSIR. To remove the reaction products on the surface of the LR-NCM, the sample obtained was washed with water several times and dried at $120^{\circ} \mathrm{C}$ for $12 \mathrm{~h}$. The as-obtained product was termed the GSIR LR-NCM. We would like to stress that the same procedures have been adopted in both NIMTE and UCSD labs, and all the electrochemical data have been completely reproduced.

Materials characterization. A field-emission scanning electron microscopy image was acquired on a Hitachi S-4800. A FTIR analysis was performed on a pellet made of active materials and $\mathrm{KBr}$ powder, using an FTIR spectrometer (Nicolet, 6700 series, USA). XPS measurements were collected using an AXIS Ultra DLD spectrometer with $\mathrm{Al} \mathrm{K} \alpha(1,253.6 \mathrm{eV})$ radiation, to investigate the changes in the compositions on the cathode surface. The compositions of the pristine, and GSIR LR-NCM sample were confirmed quantitatively by inductive coupled plasmaatomic emission spectrometry with an emission spectrometer (Optima $2100 \mathrm{DV}$, Perkin-Elmer). The tap density of the pristine LR-NCM sample was measured and calculated by tap density instrument (FSZ-4, Ruike).

TOF powder ND. The TOF powder ND data were collected on the VULCAN beamline at the Spallation Neutron Sources (SNS) in the Oak Ridge National Laboratory ${ }^{46}$. Around $0.6 \mathrm{~g}$ of powder was packed into a vanadium sample can. An incident beam $(5 \mathrm{~mm} \times 12 \mathrm{~mm})$ of 0.7 - to $3.5-\AA ̊$ bandwidth allowing a $0.5-2.5 \AA$ $\mathrm{d}$-spacing in the diffracted patterns in the $\pm 90^{\circ} 2 \theta$ detector banks was selected, using the double-disk choppers at a speed of $30 \mathrm{~Hz}$. A high-resolution mode was used with $\Delta \mathrm{d} / \mathrm{d} \sim 0.25 \%$. The SNS was at a nominal $1,100 \mathrm{~kW}$. Powder-neutrondiffraction data were collected at a high-resolution mode for $3 \mathrm{~h}$ and reduced by the 
VDRIVE software. Full-pattern Rietveld refinement was performed using the GSAS programs with the EXPGUI interface ${ }^{47}$.

TEM characterization. TEM images and EELS spectra were carried out using the JEM-ARM200CF scanning/transmission electron microscope at Brookhaven National Laboratory. The instrument is equipped with a cold field-emission source, two aberration-correctors and a high-resolution dual electron energy-loss spectrometer (Quantum GIF). The optimal energy-resolution was $\sim 0.35 \mathrm{eV}$, as judged by the full-width at half-maximum of the zero-loss peak. Spectra were recorded either using a convergent-beam in STEM mode, or parallel-beam in TEM mode, for diffraction, imaging and spectroscopy. The refinement $\mathrm{Mn} \mathrm{L}_{3}$, and $\mathrm{L}_{2}$ energy, and $\mathrm{L}_{3} / \mathrm{L}_{2}$ intensity ratio were based on Pearson's method ${ }^{48}$.

X-ray diffraction and X-ray absorption spectroscopy. SXRD data were collected using beamline BL14B1 at the Shanghai Synchrotron Radiation Facility (SSRF). These data were recorded in the $2 \theta$ range between $10^{\circ}$ and $85^{\circ}$, using a fixed wavelength of $1.2398 \AA$. The structural composite study was carried out by Rietveld refinement analysis, using the GSAS program. For X-ray absorption fine-structure spectroscopy studies, we performed measurements at beamline BL14W1 of the SSRF. The incident beam was mono-chromatized using a $\mathrm{Si}$ (111) fixed-exit, double-crystal monochromator. Foils of nickel, manganese and cobalt were used for energy calibration with zero energy $\left(E_{0}\right)$, defined according to Kraft et al. ${ }^{49}$. Spectra were acquired in transmission mode, utilizing gas-ionization chambers as detectors. Data on X-ray absorption near-edge structure was extracted with established methods using the ATHENA software package.

Electrochemical measurements. The negative electrodes were prepared by casting the slurry with a mixture of $80 \mathrm{wt} . \%$ the pristine or GSIR LR-NCM, $10 \mathrm{wt} . \%$ acetylene black and $10 \mathrm{wt} . \%$ polyvinylidene fluoride binder on an aluminium foil. Electrode discs of 13-mm diameter were punched from the negative electrode, pressed at $8 \mathrm{Mpa}$ per disc and dried at $80^{\circ} \mathrm{C}$ for $12 \mathrm{~h}$ in vacuum to remove any residual NMP and traces of water. The prepared electrodes then were assembled in an $\mathrm{Ar}$-filled glove box $\left(\mathrm{H}_{2} \mathrm{O}<0.1\right.$ p.p.m. and $\mathrm{O}_{2}<0.1$ p.p.m.). Metallic Li was used as the counter electrode, and Celgard 2502 as a separator. The electrolyte solution was $1 \mathrm{M} \mathrm{LiPF}_{6}$ in a 3:7 (volume ratio) mixture of ethylene carbonate-dimethyl carbonate (Zhangiiagang Guotai-Huarong New Chemical Materials Co., Ltd.). The cells were galvanostatically charged and discharged on a LAND-CT2001A batterytest system. Unless otherwise specified, the cells typically cycled between 2.0 and $4.8 \mathrm{~V}$ versus $\mathrm{Li}^{+} / \mathrm{Li}^{0}$, and the temperature for testing was about $28^{\circ} \mathrm{C}$. EIS measurements were performed on an Autolab83710 impedance analyser with a.c. voltage amplitude of $5 \mathrm{mV}$, and frequency range of $0.01-100,000 \mathrm{~Hz}$. The metallic Li served as both the counter and reference electrodes during the EIS measurements.

Operando DEMS. Operando DEMS analysis was carried out to detect the gases generated during the initial charge-discharge process. The DEMS cell was assembled in an Ar-filled glove box. In all, $1 \mathrm{M} \mathrm{LiPF}_{6}$ in 1:1 ethylene carbonate:dimethyl carbonate was used as the electrolyte, and a glass-fiber filter (Whatman GF/D) was used as a separator. Electrodes were prepared by casting a slurry with a composition of $80 \mathrm{wt}$ \% active materials, $10 \mathrm{wt}$ \% \% Super C65 (Timcal) and $10 \mathrm{wt} \%$ PVDF (Kynar FLEX 761A, Arkema Group) on to an aluminium current-collector foil. Electrode tapes then were punched into $22-\mathrm{mm}$ diameter discs, and dried at $120^{\circ} \mathrm{C}$ in an under vacuum oven for $24 \mathrm{~h}$. The electrodes were assembled into Swagelok-type cells, using metallic $\mathrm{Li}$ as both the counter and the reference. Thereafter, the cell was connected to the mass spectrometer. The cell was purged continuously with gaseous Ar, which flowed from the cell into the mass spectrometer carrying the evolved gases for MS analysis. Operando DEMS cells were conducted on a VSP electrochemical workstation (Biologic, France). The mass signals were recorded as a function of time and the cell voltage. The time resolution of ion-current intensity is optimized by selectively scanning the $\mathrm{m} / \mathrm{z} 32$ and 44 signals. In line with previous studies ${ }^{41,42}$, only $\mathrm{O}_{2}$ and $\mathrm{CO}_{2}$ were evolved during the initial cycling of Li-rich layered-oxide electrodes.

Computation methodology. First-principles calculations were performed in the spin-polarized GGA $+\mathrm{U}$ approximations to the density functional theory. The core electron states were represented by the projector-augmented-wave method ${ }^{50}$ as implemented in the Vienna $a b$ initio simulation package ${ }^{51-53}$. We used the PerdewBurke-Ernzerhof ${ }^{54}$ exchange correlation, and a plane-wave representation for the wave function with a cutoff energy of $450 \mathrm{eV}$. The Brillouin zone was sampled with a dense k-points mesh by Gamma packing. Our supercell, composed of 24 formula units of $\mathrm{Li}\left[\mathrm{Ni}_{1 / 4} \mathrm{Li}_{1 / 6} \mathrm{Mn}_{7 / 12}\right] \mathrm{O}_{2}$, used in our previous work was used again to obtain the site's stability and activation barrier. The Hubbard $\mathrm{U}$ correction was introduced to describe the effect of localized d electrons of the transition-metal ions. The applied effective $\mathrm{U}$ value given to $\mathrm{Mn}$ ions is $5 \mathrm{eV}$, and that to $\mathrm{Ni}$ ions is $5.96 \mathrm{eV}$ (ref. 55). In this calculation, a concentration of Li20/28 was applied, in which the GSIR LR-NCM exhibits a difference in electrochemical performance compared with pristine LR-NCM. The nudged elastic band method was used to find the minimum-energy path and the energy barrier for Li diffusion inside the materials.
Data availability. The data that support the findings of this study are available from the corresponding authors on request.

\section{References}

1. Adler, S. B. Factors governing oxygen reduction in solid oxide fuel cell cathodes. Chem. Rev. 104, 4791-4843 (2004).

2. Liao, P. \& Carter, E. A. New concepts and modeling strategies to design and evaluate photo-electro-catalysts based on transition metal oxide. Chem. Soc. Rev. 42, 2401-2422 (2013).

3. Huang, R. C. et al. Oxygen-vacancy ordering at surfaces of lithium manganese (III, IV) oxide spinel nanoparticles. Angew. Chem. Int. Ed. 50, 3053-3057 (2011).

4. Okamoto, Y. Ambivalent effect of oxygen vacancies on $\mathrm{Li}_{2} \mathrm{MnO}_{3}$ : a FirstPrinciples study. J. Electrochem. Soc. 159, A152-A156 (2012).

5. Sushko, P. V., Rosso, K. M., Zhang, J.-G., Liu, J. \& Sushko, M. L. Oxygen vacancies and ordering of d-levels control voltage suppression in oxide cathodes: the case of spinel $\mathrm{LiNi}_{0.5} \mathrm{Mn}_{1.5} \mathrm{O}_{4-\delta}$. Adv. Funct. Mater. 23, 5530-5535 (2013).

6. Kim, J.-H., Myung, S.-T., Yoon, C. S., Kang, S. G. \& Sun, Y.-K. Comparative study of $\mathrm{LiNi}_{0.5} \mathrm{Mn}_{1.5} \mathrm{O}_{4-\delta}$ and $\mathrm{LiNi}_{0.5} \mathrm{Mn}_{1.5} \mathrm{O}_{4}$ cathodes having two crystallographic structures: Fd-3m and $\mathrm{P}_{3} 32$. Chem. Mater. 16, $904-916$ (2007).

7. Jung, S.-K. et al. Understanding the degradation mechanisms of $\mathrm{LiNi}_{0.5} \mathrm{Co}_{0.2} \mathrm{Mn}_{0.3} \mathrm{O}_{2}$ cathode material in lithium ion batteries. Adv. Energy Mater. 4, 201300787 (2014).

8. Lin, F. et al. Surface reconstruction and chemical evolution of stoichiometric layered cathode materials for lithium-ion batteries. Nat. Commun. 5, 3529 (2014).

9. Yu, H. et al. Direct atomic-resolution observation of two phases in the $\mathrm{Li}_{1.2} \mathrm{Mn}_{0.567} \mathrm{Ni}_{0.166} \mathrm{Co}_{0.067} \mathrm{O}_{2}$ cathode material for lithium-ion batteries. Angew. Chem. Int. Ed. 52, 5969-5973 (2013).

10. Johnson, C. S. et al. The significance of the $\mathrm{Li}_{2} \mathrm{MnO}_{3}$ component in 'composite' $\mathrm{xLi}_{2} \mathrm{MnO}_{3} \cdot(1-\mathrm{x}) \mathrm{LiMn}_{0.5} \mathrm{Ni}_{0.5} \mathrm{O}_{2}$ electrodes. Electrochem. Commun. 6, 1085-1091 (2004).

11. Thackeray, M. M. et al. $\mathrm{Li}_{2} \mathrm{MnO}_{3}$-stabilized $\mathrm{LiMO}_{2}(\mathrm{M}=\mathrm{Mn}, \mathrm{Ni}, \mathrm{Co})$ electrodes for lithium-ion batteries. J. Mater. Chem. 17, 3112-3125 (2007).

12. Rossouw, M. H. \& Thackeray, M. M. Lithium manganese oxides from $\mathrm{Li}_{2} \mathrm{MnO}_{3}$ for rechargeable lithium battery applications. Mater. Res. Bull. 26, 463-473 (1991).

13. Lu, Z., MacNeil, D. D. \& Dahn, J. R. Layered cathode materials $\operatorname{Li}\left[\mathrm{Ni}_{\mathrm{x}} \mathrm{Li}_{1 / 3-2 \mathrm{x}}\right.$ $\left.{ }_{3} \mathrm{Mn}_{2 / 3-\mathrm{x} / 3}\right] \mathrm{O}_{2}$ for lithium-ion batteries. Electrochem. Solid-State Lett. 4, A191-A194 (2001)

14. Xia, Q. et al. A Li-rich layered@spinel@carbon heterostructured cathode material for high capacity and high rate lithium-ion batteries fabricated via an in situ synchronous carbonization-reduction method. J. Mater. Chem. A 3, 3995-4003 (2015).

15. Hy, S. et al. Performance and design considerations for lithium excess layered oxide positive electrode materials for lithium ion batteries. Energy Environ. Sci. 9, 1931-1954 (2016).

16. Ohzuku, T., Nagayama, M., Tsuji, K. \& Ariyoshi, K. High-capacity lithium insertion materials of lithium nickel manganese oxides for advanced lithiumion batteries: toward rechargeable capacity more than $300 \mathrm{mAh} \mathrm{g}^{-1}$. J. Mater. Chem. 21, 10179-10188 (2011).

17. Lu, Z. \& Dahn, J. R. Understanding the anomalous capacity of $\mathrm{Li} / \mathrm{Li}\left[\mathrm{Ni}_{\mathrm{X}} \mathrm{Li}_{1 / 3-2 \mathrm{x} /}\right.$ $\left.{ }_{3} \mathrm{Mn}_{2 / 3-\mathrm{x} / 3}\right] \mathrm{O}_{2}$ cells using in situ $\mathrm{X}$-ray diffraction and electrochemical studies. J. Electrochem. Soc. 149, A815-A822 (2002).

18. Armstrong, A. R. et al. Demonstrating oxygen loss and associated structural reorganization in the lithium battery cathode $\mathrm{Li}\left[\mathrm{Ni}_{0.2} \mathrm{Li}_{0.2} \mathrm{Mn}_{0.6}\right] \mathrm{O}_{2}$. J. $A m$. Chem. Soc. 128, 8694-8698 (2006).

19. Koga, H. et al. Reversible oxygen participation to the redox processes revealed for $\mathrm{Li}_{1.2} \mathrm{Mn}_{0.54} \mathrm{Co}_{0.13} \mathrm{Ni}_{0.13} \mathrm{O}_{2}$. J. Electrochem. Soc. 160, A786-A792 (2013).

20. Koga, H. et al. Different oxygen redox participation for bulk and surface: a possible global explanation for the cycling mechanism of $\mathrm{Li}_{1.20} \mathrm{Mn}_{0.54} \mathrm{Co}_{0.13} \mathrm{Ni}_{0.13} \mathrm{O}_{2}$. J. Power Sources 236, 250-258 (2013).

21. Sathiya, M. et al. High performance $\mathrm{Li}_{2} \mathrm{Ru}_{1-\mathrm{y}} \mathrm{Mn}_{\mathrm{y}} \mathrm{O}_{3}(0.2 \leq \mathrm{y} \leq 0.8)$ cathode materials for rechargeable lithium-ion batteries: their understanding. Chem. Mater. 25, 1121-1131 (2013).

22. Sathiya, M. et al. Reversible anionic redox chemistry in high-capacity layeredoxide electrodes. Nat. Mater. 12, 827-835 (2013).

23. Oishi, M. et al. Direct observation of reversible charge compensation by oxygen ion in Li-rich manganese layered oxide positive electrode material, $\mathrm{Li}_{1.16} \mathrm{Ni}_{0.15} \mathrm{Co}_{0.19} \mathrm{Mn}_{0.50} \mathrm{O}_{2}$. J. Power Sources 276, 89-94 (2015).

24. Xu, B., Fell, C. R., Chi, M. \& Meng, Y. S. Identifying surface structural changes in layered Li-excess nickel manganese oxides in high voltage lithium ion batteries: a joint experimental and theoretical study. Energy Environ. Sci. 4, 2223-2233 (2011). 
25. Fell, C. R. et al. Correlation between oxygen vacancy, microstrain, and cation distribution in lithium-excess layered oxides during the first electrochemical cycle. Chem. Mater. 25, 1621-1629 (2013).

26. Qian, D., Xu, B., Chi, M. \& Meng, Y. S. Uncovering the roles of oxygen vacancies in cation migration in lithium excess layered oxides. Phys. Chem. Chem. Phys. 16, 14665-14668 (2014).

27. Kubota, K. et al. Direct synthesis of oxygen-deficient $\mathrm{Li}_{2} \mathrm{MnO}_{3-\mathrm{x}}$ for high capacity lithium battery electrodes. J. Power Sources 216, 249-255 (2012).

28. Song, B. et al. High rate capability caused by surface cubic spinels in Li-rich layer-structured cathodes for Li-ion batteries. Sci. Rep. 3, 3094-3105 (2013).

29. Kang, S. H., Johnson, C. S., Vaughey, J. T., Amine, K. \& Thackeray, M. M. The effects of acid treatment on the electrochemical properties of $0.5 \mathrm{Li}_{2} \mathrm{MnO}_{3}$ $0.5 \mathrm{LiNi}_{0.44} \mathrm{Co}_{0.25} \mathrm{Mn}_{0.31} \mathrm{O}_{2}$ electrodes in lithium cells. J. Electrochem. Soc. 153, A1186-A1192 (2006).

30. Zhao, J. et al. An ion-exchange promoted phase transition in a Li-excess layered cathode material for high-performance lithium ion batteries. Adv. Energy Mater 5, 201401937 (2015).

31. Yu, D. Y. W., Yanagida, K. \& Nakamura, H. Surface modification of Li-excess Mn-based cathode materials. J. Electrochem. Soc. 157, A1177-A1182 (2010).

32. Sun, Y. K. et al. The role of $\mathrm{AlF}_{3}$ coatings in improving electrochemical cycling of Li-enriched nickel-manganese oxide electrodes for Li-ion batteries. Adv. Mater. 24, 1192-1196 (2012).

33. Villevieille, C., Lanz, P., Bünzli, C. \& Novák, P. Bulk and surface analyses of ageing of a $5 \mathrm{~V}-\mathrm{NCM}$ positive electrode material for lithium-ion batteries. J. Mater. Chem. A 2, 6488-6493 (2014).

34. Yabuuchi, N., Yoshii, K., Myung, S. T., Nakai, I. \& Komaba, S. Detailed studies of a high-capacity electrode material for rechargeable batteries, $\mathrm{Li}_{2} \mathrm{MnO}_{3}-\mathrm{LiCo}_{1 /}$ ${ }_{3} \mathrm{Ni}_{1 / 3} \mathrm{Mn}_{1 / 3} \mathrm{O}_{2}$. J. Am. Chem. Soc. 133, 4404-4419 (2011).

35. Qiu, B. et al. Enhanced electrochemical performance with surface coating by reactive magnetron sputtering on lithium-rich layered oxide electrodes. ACS Appl. Mater. Interfaces 6, 9185-9193 (2014).

36. Liu, H., Fell, C. R., An, K., Cai, L. \& Meng, Y. S. In situ neutron diffraction study of the $\mathrm{xLi}_{2} \mathrm{MnO}_{3} \cdot(1-\mathrm{x}) \mathrm{LiMO}_{2}(\mathrm{x}=0,0.5 ; \mathrm{M}=\mathrm{Ni}, \mathrm{Mn}, \mathrm{Co})$ layered oxide compounds during electrochemical cycling. J. Power Sources 240, 772-778 (2013).

37. Wu, L. J. et al. Structural defects of silver hollandite, $\mathrm{Ag}_{\mathrm{x}} \mathrm{Mn}_{8} \mathrm{O}_{\mathrm{y}}$, nanorods: dramatic impact on electrochemistry. ACS Nano 9, 8430-8439 (2015).

38. Arunkumar, T. A., Wu, Y. \& Manthiram, A. Factors influencing the irreversible oxygen loss and reversible capacity in layered $\mathrm{Li}\left[\mathrm{Li}_{1 / 3} \mathrm{Mn}_{2 / 3}\right] \mathrm{O}_{2}-\mathrm{Li}[\mathrm{M}] \mathrm{O}_{2}$ $\left(\mathrm{M}=\mathrm{Mn}_{0.5-\mathrm{y}} \mathrm{Ni}_{0.5-\mathrm{y}} \mathrm{Co}_{2 \mathrm{y}}\right.$ and $\left.\mathrm{Ni}_{1-\mathrm{y}} \mathrm{Co}_{\mathrm{y}}\right)$ solid solutions. Chem. Mater. 19, 3067-3073 (2007).

39. Wu, Y. \& Manthiram, A. High capacity, surface-modified layered $\operatorname{Li}\left[\operatorname{Li}_{(1-x) /}\right.$ $\left.{ }_{3} \mathrm{Mn}_{(2-\mathrm{x}) / 3} \mathrm{Ni}_{\mathrm{x} / 3} \mathrm{Co}_{\mathrm{x} / 3}\right] \mathrm{O}_{2}$ cathodes with low irreversible capacity loss. Electrochem. Solid-State Lett. 9, A221-A224 (2006).

40. Liu, W. et al. Countering voltage decay and capacity fading of lithium-rich cathode material at $60^{\circ} \mathrm{C}$ by hybrid surface protection layers. Adv. Energy Mater. 5, 201500274 (2015).

41. Lanz, P., Sommer, H., Schulz-Dobrick, M. \& Novák, P. Oxygen release from high-energy $\mathrm{xLi}_{2} \mathrm{MnO}_{3}-(1-\mathrm{x}) \mathrm{LiMO}_{2}(\mathrm{M}=\mathrm{Mn}, \mathrm{Ni}, \mathrm{Co})$ : electrochemical, differential electrochemical mass spectrometric, in situ pressure, and in situ temperature characterization. Electrochim. Acta 93, 114-119 (2013).

42. Castel, E., Berg, E. J., El Kazzi, M., Novák, P. \& Villevieille, C. Differential electrochemical mass spectrometry study of the interface of $\mathrm{xLi}_{2} \mathrm{MnO}_{3}$. $(1-\mathrm{x}) \mathrm{LiMO}_{2}(\mathrm{M}=\mathrm{Ni}, \mathrm{Co}$, and $\mathrm{Mn})$ material as a positive electrode in $\mathrm{Li}$-ion batteries. Chem. Mater. 26, 5051-5057 (2014).

43. Yu, H. et al. Electrochemical kinetics of the $0.5 \mathrm{Li}_{2} \mathrm{MnO}_{3}$ $0.5 \mathrm{LiMn}_{0.42} \mathrm{Ni}_{0.42} \mathrm{Co}_{0.16} \mathrm{O}_{2}$ 'composite' layered cathode material for lithium-ion batteries. RSC Adv. 2, 8797-8807 (2012).

44. Kang, K., Meng, Y. S., Breger, J., Grey, C. P. \& Ceder, G. Electrodes with high power and high capacity for rechargeable lithium batteries. Science 311, 977-980 (2006).

45. Qiu, B. et al. Electrochemical investigation of Li-excess layered oxide cathode materials/mesocarbon microbead in 18650 batteries. Electrochim. Acta 123, 317-324 (2014)

46. An, K., Wang, X. L. \& Stoica, A. D. Vulcan data reduction and interactive visualization software, ORNL Report, 621 (2012).

47. Toby, B. H. EXPGUI, a graphical user interface for GSAS. J. Appl. Crystallogr. 34, 210-213 (2001).

48. Pearson, D. H. et al. White lines and d-electron occupancies for the $3 \mathrm{~d}$ and $4 \mathrm{~d}$ transition metals. Phys. Rev. B: Condens. Matter Mater. Phys. 47, 8471-8478 (1993).
49. Kraft, S., Stümpel, J., Becker, P. \& Kuetgens, U. High resolution X-ray absorption spectroscopy with absolute energy calibration for the determination of absorption edge energies. Rev. Sci. Instrum. 67, 681-687 (1996).

50. Kresse, G. \& Joubert, D. From ultrasoft pseudopotentials to the projector augmented-wave method. Phys. Rev. B 59, 1758-1775 (1999).

51. Kresse, G. \& Furthmüller, J. Efficiency of $a b$-initio total energy calculations for metals and semiconductors using a plane-wave basis set. Comp. Mater. Sci. 6, 15-50 (1996).

52. Kresse, G. \& Furthmüller, J. Efficient iterative schemes for $a b$ initio totalenergy calculations using a plane-wave basis set. Phys. Rev. B 54, 11169-11186 (1996).

53. Kresse, G. \& Hafner, J. $A b$ initio molecular-dynamics simulation of the liquidmetal-amorphous-semiconductor transition in germanium. Phys. Rev. B 49, 14251-14269 (1994).

54. Perdew, J. P., Burke, K. \& Wang, Y. Generalized gradient approximation for the exchange-correlation hole of a many-electron system. Phys. Rev. B 54, 16533-16539 (1996).

55. Hinuma, Y., Meng, Y. S., Kang, K. \& Ceder, G. Phase transitions in the $\mathrm{LiNi}_{0.5} \mathrm{Mn}_{0.5} \mathrm{O}_{2}$ system with temperature. Chem. Mater. 19, 1790-1800 (2007).

\section{Acknowledgements}

NIMTE is grateful for financial support from Strategic Priority Research Program of Chinese Academy of Sciences (CAS, Grant No. XDA09010101), Key Projects in Cooperation between CAS and Department of Energy, USA (CAS-DOE, Grant No. 174433KYSB20150047), and Ningbo Science and Technology Innovation Team (Grant No. 2012B82001). UC San Diego's efforts are supported by the Assistant Secretary for Energy Efficiency and Renewable Energy, Office of Vehicle Technologies of the U.S. Department of Energy (DOE) under Contract No. DE-AC02-05CH11231, Subcontract No. 7073923, under the Advanced Battery Materials Research (BMR) Program. Work at Brookhaven National Laboratory is supported by the U.S. DOE, Office of Basic Energy Science, Division of Materials Science and Engineering, under Contract No. DE-AC0298CH10886. The synchrotron XRD and XAS measurements were carried out at SSRF of the beamline BL14B1 and BL14W1, respectively. The neutron experiments benefit from the SNS user facilities (VULCAN beamline) sponsored by the office of Basic Energy Sciences (BES), the Office of Science of the U.S. DOE. We acknowledge Dr Ding-Yi Tong for the design of the schematic.

\section{Author contributions}

B.Q. prepared the samples. M.Z., H.L. and Y.S.M. performed the mechanism analysis. B.Q. and M.Z. tested the electrochemical performances and performed analysis. L.W. and Y.Z performed the electron microscopy imaging, diffraction and spectroscopy experiments and analyses. J.W. performed the operando mass spectrometry analysis. D.Q. and Y.S.M. performed the first-principles calculations. H.L., Y.C., K.A. and S.H. recorded ND experiment data and analyses. Z.L., Y.S.M., and Y.X. supervised the research. B.Q. and M.Z. co-wrote the manuscript. All authors contributed to the discussion and provided feedback on the manuscript.

\section{Additional information}

Supplementary Information accompanies this paper at http://www.nature.com/ naturecommunications

Competing financial interests: The authors declare no competing financial interests.

Reprints and permission information is available online at http://npg.nature.com/ reprintsandpermissions/

How to cite this article: Qiu, B. et al. Gas-solid interfacial modification of oxygen activity in layered oxide cathodes for lithium-ion batteries. Nat. Commun. 7:12108 doi: 10.1038/ncomms12108 (2016).

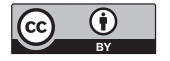

This work is licensed under a Creative Commons Attribution 4.0 International License. The images or other third party material in this article are included in the article's Creative Commons license, unless indicated otherwise in the credit line; if the material is not included under the Creative Commons license, users will need to obtain permission from the license holder to reproduce the material. To view a copy of this license, visit http://creativecommons.org/licenses/by/4.0/

(C) The Author(s) 2016 